\title{
The Impact of Vocational Schooling on Human Capital Development in Developing Countries: Evidence from China
}

\author{
Prashant Loyalka, Xiaoting Huang, Linxiu Zhang, Jianguo Wei, \\ Hongmei Yi, Yingquan Song, Yaojiang Shi, and James Chu
}

\begin{abstract}
A number of developing countries are currently promoting vocational education and training (VET) as a way to build human capital and strengthen economic growth. The primary aim of this study is to understand whether VET at the high school level contributes to human capital development in one of those countries-China. To fulfill this aim, we draw on longitudinal data on more than 10,000 students in vocational high school (in the most popular major, computing) and academic high school from two provinces of China. First, estimates from instrumental variables and matching analyses show that attending vocational high school (relative to academic high school) substantially reduces math skills and does not improve computing skills. Second, heterogeneous effect estimates also show that attending vocational high school increases dropout, especially among disadvantaged (low-income or low-ability) students. Third, we use vertically scaled (equated) baseline and follow-up test scores to measure gains in math and computing skills among the students. We find that students who attend vocational high school experience absolute reductions in math skills. Taken together, our findings suggest that the rapid expansion of vocational schooling as a substitute for academic schooling can have detrimental consequences for building human capital in developing countries such as China. JEL codes: I25, J24, O15
\end{abstract}

Prashant Loyalka is a research fellow at Freeman Spogli Institute for International Studies and a faculty member of the Rural Education Action Program (REAP) at Stanford University; his email address is loyalka@stanford.edu. Xiaoting Huang is an associate professor at China Institute for Educational Finance Research (CIEFR), Peking University, China; her email address is xthuang@ciefr.pku.edu.cn. Linxiu Zhang is professor and deputy director of Center for Chinese Agricultural Policy (CCAP), Institute for Geographical Sciences and Natural Resources Research (IGSNRR), Chinese Academy of Sciences (CAS), China; her email address is lxzhang.ccap@igsnrr.ac.cn. Jianguo Wei is an associate professor at CIEFR, Peking University, China; his email address is jgwei@ciefr.pku.edu.cn. Hongmei Yi (corresponding author) is an associate professor of CCAP, IGSNRR, CAS, China; her email address is yihm.ccap@igsnrr.ac.cn. Yingquan Song is an associate professor at CIEFR, Peking University, China; his email address is yqsong@ciefr.pku.edu.cn. Yaojiang Shi is professor and director of Center for Experimental Economics of Education, Shaanxi Normal University, China. James Chu is project manager of REAP at Stanford University, his email address is jchu1225@stanford.com. The authors gratefully acknowledge the financial assistance of the National Natural Science Foundation of China (No. 71110107028 and 71573246), 3ie, and the Ford Foundation. A supplemental appendix to this article is available at http://wber.oxfordjournals.org/.

THE WORLD BANK ECONOMIC REVIEW, VOL. 30, NO. 1, pp. 143-170

doi:10.1093/wber/lhv050

Advance Access Publication August 27, 2015

(C) The Author 2015. Published by Oxford University Press on behalf of the International Bank

for Reconstruction and Development / THE WORLD BANK. All rights reserved. For permissions, please e-mail: journals.permissions@oup.com. 
As the economies of developing countries shift from lower value-added to higher value-added industries and experience technological change, their need for human capital also increases (Heckman and Yi 2012). Higher value-added jobs must be staffed with employees who are equipped with greater skills (Bresnahan et al. 2002). Without a labor force with sufficient skills, developing economies could ultimately stagnate (Hanushek and Woessman 2012).

A number of developing countries identify vocational education and training (VET) as a key approach to building human capital. For example, the promotion of VET at the high school level (or "vocational high school") has become a policy priority among emerging economies such as Brazil, Indonesia, and China (Newhouse and Suryadarma 2011; National Congress of Brazil 2011; China State Council 2010). Over the past decade, these countries have increased funding and enrollments in vocational high school (often in lieu of academic high school-e.g., Indonesia, see Newhouse and Suryadarma 2011). The rationale underlying these policies is that increases in the proportion of vocationalas opposed to academic_-high school enrollments can more effectively build human capital.

For VET to successfully build human capital in these countries, however, it must meet two prerequisites. The first prerequisite is that VET must help students learn specific (vocational) skills that can either directly be used in the labor market after graduation or serve as a foundation for vocational college (Kuczera et al. 2008). Second, VET must help students acquire general skills (e.g., in math, reading, and/or science-Chiswick, Lee, and Miller 2003). The international literature shows that a solid foundation of general skills has a significant and longterm impact on the wages of high school graduates (Levy and Murnane 2004). Research also suggests that job stability for individuals (as well as economic stability for countries) requires lifelong learning, which is contingent on a foundation in general skills (Kezdi 2006). For these reasons, almost all countries require vocational high schools to teach general skills (Kuczera et al. 2008).

Surprisingly, there is little evidence from developing countries as to whether vocational high school helps students acquire specific and general skills, especially in comparison to academic high school. Cross-national studies based on international tests such as the PISA show that students in vocational high school have lower levels of general skills than students in academic high school (by almost half a standard deviation, see Altinok 2011). However, since the PISA data do not contain detailed information on student background characteristics (such as prior test scores) that are necessary to adjust for selection bias, the PISA data are not suitable for measuring the causal impacts of attending vocational versus academic high school. Furthermore, because the PISA data are cross-sectional and not longitudinal, they cannot show how much vocational high school contributes to gains in student learning.

One exception uses longitudinal data from Indonesia in the 1990s to show that attending vocational school has little impact on students' general skills (Chen 2009). Unfortunately, the Chen study relies on a sample of students 
smaller than 1,000. Because this sample does not have sufficient vocational and academic high school students that share a common set of characteristics, the OLS regressions used in the study may give biased results (as they are based on linear extrapolations away from a common support-King and Zeng 2006).

In this paper, we examine whether vocational high school students are learning specific and/or general skills. We seek to accomplish three goals. First, we seek to assess the impact of attending vocational versus academic high school on the dropout rates, math, and computing skills of the average student. Second, we seek to estimate the heterogeneous impacts of attending vocational versus academic high school on the dropout rates and skill levels of disadvantaged (lowincome or low-ability) students. Third, we aim to establish whether vocational high school leads to any absolute gains in math and computing skills.

To accomplish these aims, we conduct analyses using longitudinal data on more than 10,000 students in China. Estimates from instrumental variables and matching analyses show that attending the most popular major in Chinese vocational schools (computers) relative to attending academic high school substantially reduces math skills without improving computing skills. Attending vocational high school also increases dropout, especially among disadvantaged (low-income and low-ability) students. We also use comparable (equated or scaled) baseline and follow-up test scores to measure students' absolute gains in math and computing skills. We find that computing major students who attend vocational high school experience absolute reductions in math. Taken together, our findings indicate that the promotion of vocational schooling as a substitute for academic schooling may be detrimental to building human capital in developing countries such as China.

\section{B ACKGROUND}

Like many other developing countries, policymakers in China have a strong interest in using VET to build human capital and drive economic growth (China State Council 2010). This interest has resulted in the expansion of vocational high school enrollments from 11.7 to 22.1 million students between 2001 and 2011 and annual investments of more than 21 billion dollars (NBS various years; MOF and NBS 2011). Policymakers in China also hope to use VET to help disadvantaged (low-income or low-ability) students gain employment (China State Council 2010). It is for this reason that policymakers have provided financial aid to all vocational high school students and waived tuition for low-income vocational high school students in particular (China State Council 2010; MOF and MOE 2006).

What are vocational high schools supposed to accomplish? Vocational high school students are trained to become mid-level skilled workers. By policy design, the computer major in China is set up to train workers for entry level jobs in database management, website administration, software engineering, advertising (layout, photo-editing), or computer animation (Chinese Ministry of 
Education 2008). This differs from academic high school, which trains students in academic or general skills, mainly for entry into higher education.

In terms of curriculum, vocational high school students in the first year of the computing major are supposed to spend roughly equal amounts of time on academic and computing skills. ${ }^{1}$ In their second year, students spend the majority of their time on computing skills. Students spend the third year in internships.

Academic high schools, by contrast, are focused on academic subjects tested on the college entrance examination, with roughly only $10 \%$ of time spent on subjects like music, computers, or physical exercise.

How do students choose to attend vocational high school? After graduating from junior high, students decide between entering the labor market, vocational high school, or academic high school. In China, the level of a student's high school entrance examination (HSEE) score is the primary determinant for entry into academic high school. Every county ostensibly has a cutoff for whether a student's score makes him/her eligible to enter academic high school (based on the number of positions in academic high school available that year). Those who test below the cutoff are unable to attend academic high school and must choose whether to enter the labor market or vocational high school. Those students that test just above the cutoff sometimes waver between whether to attend vocational or academic high school. Those who test far above the cutoff almost always attend academic high school.

\section{ReSEARCH DESIGN}

\subsection{Sampling}

This paper draws on longitudinal survey data collected by the authors in October 2011 and May 2012. The sample for the longitudinal survey was chosen in several steps and covers vocational and academic high schools in different regions of China. First, we sampled two provinces in China: Shaanxi and Zhejiang. Shaanxi province is an inland province in Northwest China and ranks fifteenth out of thirty-one provinces in terms of GDP per capita (NBS 2012). Zhejiang is a coastal province that ranks fifth in terms of GDP per capita (NBS 2012). After selecting the two provinces, we sampled the most populous prefectures within each province (three in Shaanxi and four in Zhejiang) and all the counties in those prefectures. ${ }^{2}$ In sum, we sampled two provinces, seven prefectures in those provinces, and the seventy-five counties in those prefectures. ${ }^{3}$

1. All VET curricula are based on national standards (such as those from the Ministry of Education, which publishes a detailed list of standards for all facilities, textbooks, and software required for instruction-Chinese Ministry of Education 2008).

2. In contemporary China each province is split into multiple prefectures, which are in turn split into counties.

3. Note that the seven prefectures in our sample contain seventy-five counties. Since not every one of these counties had a vocational school or a vocational school with the computing major, the schools in our sample were distributed in thirty-five of the seventy-five total counties. 
We next sampled vocational high schools from the seven prefectures. According to administrative records, there were 204 and 285 vocational schools in the sample prefectures in Shaanxi and Zhejiang, respectively. Using administrative records, we included all vocational high schools that offered a computer major in our sample. We focused on the computer major for two reasons. First, computing is studied in academic high schools (albeit to a lesser degree), which allows us to compare learning gains in specific skills (i.e., computers) across vocational and academic high schools. Second, the computer major is the major with the largest number of enrollments in the two provinces. Over half of all vocational high schools had computing majors, and we only had to exclude 101 schools in Shaanxi and 133 schools in Zhejiang due to the fact that they did not offer computer majors.

After selecting vocational high schools with computing majors, we called these schools to ask how many new (grade ten) students enrolled in autumn 2011. Schools that reported fewer than fifty grade ten students enrolled in the computer major were excluded from our sampling frame. ${ }^{4}$ This criterion meant that we excluded fifty-six schools in Shaanxi and seventy-eight schools in Zhejiang. Although the number of excluded schools was higher than we expected, these small schools comprised less than $15 \%$ of the share of computing students in Shaanxi and Zhejiang. We then enrolled the remaining forty-six schools in Shaanxi and fifty-five schools in Zhejiang in our sample.

We concurrently sampled academic high schools in the seven prefectures. We found 104 and 155 academic high schools in the sample prefectures in Shaanxi and Zhejiang, respectively. Because we planned to match vocational and academic high school students, we needed a sample of academic high school students that might have considerable overlap in basic student characteristics across the two types of high schools. To achieve this goal, we excluded elite academic high schools from our sample. In China, elite academic high schools select students of much higher ability than nonelite academic high schools. Few (if any) students that are eligible for elite academic high schools would ever consider going to vocational high school. Because students currently enrolled in nonelite academic high school were more likely to have considered attending vocational high schools, we only sampled nonelite academic high schools.

Given these criteria for academic high school, we then selected our sample. Within the seven prefectures, there were sixty-two and eighty-eight nonelite academic high schools in Shaanxi and Zhejiang (about $60 \%$ of all academic high schools). From these schools, we randomly sampled fifteen eligible nonelite academic high schools from each province (thirty schools in total).

The next step was to choose which students would be surveyed within the sample schools. In each vocational high school, we randomly sampled two firstyear computer major classes (one class if the school only had one computer major class) and surveyed all students in these classes. In each nonelite academic

4. We excluded these small schools because policymakers informed us that such schools were at high risk of being closed or merged during the school year. 
high school, we randomly sampled two first-year classes and surveyed all students in these classes.

\subsection{Data Collection}

Our data collection started with a baseline (October 2011) survey. The baseline survey collected data from students, students' homeroom teachers, and school principals. Among vocational high schools, 7,114 first-year students in 184 classes filled out the baseline survey. Among academic high schools, 2,957 students in fifty-nine classes filled out the baseline survey. ${ }^{5}$ In total, we surveyed 10,071 students $(7114+2957)$.

We followed up with the sample vocational and academic high school students in May 2012 (hereafter known as the endline survey). The survey forms used in the endline survey were similar to those used in the baseline survey. Most importantly, our data allowed us to create three primary outcome variables: (a) student dropout (whether a student was enrolled in a high school as of May 2012); (b) student gains in computing skills (according to a standardized exam); and (c) student gains in math skills (according to a standardized exam).

Our first outcome was whether a student (who had started high school in October 2011) had dropped out by May 2012. To identify dropouts, our enumerators filled in a student-tracking form for each class during the endline survey. This form contained a list of all the students who completed our baseline survey. Our enumerators marked each student on the baseline list as present, absent, transferred, on leave, or dropped out, according to information provided by class monitors. Moreover, after the field survey was over, our enumerators called the parents or guardians of the students to further ascertain whether the students marked as dropped out on our tracking form had in fact dropped out.

A multi-step procedure was used to ensure that the computing and math tests were valid (and represented the types of skills that students were expected to acquire in high schools in China). First, we collected a pool of over 200 computer and math exam items (questions) from official sources. ${ }^{6}$ Because the test items were based on national standards, they are (according to policy) supposed to be reflected in the content actually taught in school. Second, to further verify the content validity of the items, we asked vocational high school teachers to ensure that the items were relevant to what computer majors would actually be learning in vocational high school. Third, after piloting the large pool of exam items with more than 300 students, we designed vertically scaled (equated) baseline and endline exams using item response theory (IRT). By using the IRT procedure suggested by Kolen and Brennan (2004), we were able to ensure that baseline and

5. Because of low enrollments, there was one academic high school (out of the 30) that only had one class (instead of 2). This explains why there are fifty-nine classes as opposed to sixty.

6. Specifically, the computer exam items were taken from the previous year's National Computer Rank Examination and the National Applied Information Technology Certificate exams. The math exam items were provided by the National Examination Center and closely matched the current curricular requirements of high school students in China. 
endline exam scores could be compared on a common scale. Placing the baseline and endline exam scores on a common scale allows us to measure absolute gains (or losses) in learning from the start of grade ten until the end of grade ten.

We administered and closely proctored the standardized computer and math exams during the baseline (October 2011) and endline surveys (May 2012). The exam scores were then normalized into z-scores (for computers and math separately and for the baseline and endline exams separately) by subtracting the mean and dividing by the standard deviation (SD) of the exam score distribution. ${ }^{7}$

In addition to gathering data on our outcome variables, our survey included three blocks pertaining to student background characteristics. The first block asked students to report their gender, age, whether their household registration (urban) status was rural or urban, and whether they had migrated before. As a part of this block, we also asked students to report their HSEE scores, the year they took the examination, and the prefecture where they took the examination. ${ }^{8}$

The second block gathered information on students' families. This block included parental education level (a dummy indicator equal to 1 if neither parent finished junior high and 0 otherwise), parental migration status (whether both parents stayed at home between January 2011 to August 2011), and whether the student had any siblings.

The third block was used to identify whether students were from low-income backgrounds. Students were asked to fill out a checklist of household durable assets. We used principal components analysis, adjusting for the fact that the variables are dichotomous and not continuous, to calculate a single metric of the "family asset value" for each student (see Kolenikov and Angeles 2009).9" Low-income students are defined as those students whose family asset value was in the bottom $33 \%$ of the sample.

Before conducting any analyses, we trim observations that, for substantive reasons, clearly lie outside the common support shared by academic and vocational high school students. As detailed in our analysis section below, students

7. Although it is standard in education studies, we did not implement a reading test because principals and local education administrators were concerned that the time of the survey would be too long. Likewise, our Institutional Review Board was concerned that we would take too much instructional time away from our respondents by adding a third test.

8. Students are unlikely to suffer from recall bias when reporting on their HSEE scores because they received their scores only two months before the time of the survey. Granted, it is possible that vocational students remembered their scores as being lower than they actually were precisely because they ended up in vocational school. However, this would bias the results toward finding a positive effect of vocational school. As such, it would not challenge the findings of the paper.

9. We conduct standard robustness tests to see whether the use of polychoric PCA results in a viable family wealth metric. First, we find that the first principal component explains a large proportion of the variance in the family asset variables. The second and remaining principal components explain little of the variance. This indicates that the poverty metric reflects a common relationship underlying the inputs (wealth). Second, the scoring coefficients on the first principal component for each asset indicator all run in the anticipated directions. This means that the possession of assets indicates a higher first principal component score (wealth). Third, we find no evidence of clumping or truncation in our family wealth metric. 
with extreme ages and test scores or that did not take the HSEE are dropped from the analyses. Thus, of the original 10,071 students, we first trimmed 263 students who scored in the bottom and top $1 \%$ of the baseline math and computer score distributions. Second, we trimmed away another 137 students whose age is outside the normal range for high school (roughly fourteen to nineteen years old). We further trimmed students that did not take the HSEE (1,279 students) or those who took the HSEE in years other than 2010 or 2011 (748 students). These students made schooling choices (whether or not to take the HSEE and thus apply for academic high school; whether or not to take the HSEE "on time" like "regular" students aspiring to go to academic high school) that were clearly different from academic high school students. By trimming away these students, we effectively controlled for school choice (between vocational and academic high school) before conducting our matching analyses. In total, there were 7,644 students remaining after our trimming procedure.

The attrition rate in our analytical sample was low. Of the 7,644 in our analytical sample, 367 students (4.8\% of the sample) were absent (305) or on longterm sick leave (sixty-two). Another group of 583 students (or roughly $8 \%$ of the analytical sample) dropped out. For the students who dropped out, we recorded their dropout status and thus include them in our analyses of the impacts of attending vocational (versus academic) high school on dropout. However, measures of the computing and math skills of dropouts are missing for such students.

We also test for attrition in appendix table S1 (appendix table S1 in the supplemental appendix, available at http://wber.oxfordjournals.org/). From appendix table S1, we can see that the attriting students (the majority of which are dropouts) differ from non-attriting students in baseline characteristics. Specifically, attritors were more likely to be male (column 2, significant at the $10 \%$ level), older (column 3, significant at the 5\% level), have parents who are not at home (column 7 , significant at the $1 \%$ level), have lower math scores (column 9, significant at the 1\% level), and have lower computer scores (column 10 , significant at the $10 \%$ level). Although there is imbalance between attriting and non-attriting students, the imbalance does not appear to bias our results. In particular, we estimate Lee Bounds (that account for problematic attrition) for the endline math and endline computer achievement outcomes (see our robustness check subsection 3.1.2 below).

As our study did not randomly assign students (to academic high school and vocational high school), we do not expect to see balance between the students that attended vocational high school and those that attended academic high school. Indeed, the groups differ substantially in terms of baseline characteristics (table 1). Vocational high school students are less likely to be among students with the lowest incomes (row 4), tend to be older (row 6), and have parents that tend to have migrated in the past (row 8). Moreover, their parents are less likely to have completed junior high (row 11). Although their math scores are much lower than academic high students at the baseline (row 12), their computer scores are slightly higher (row 13). Because of these differences, outcomes such 
Table 1. Differences between Vocational High School and Academic High School Students

\begin{tabular}{lccc}
\hline & $(1)$ & $(2)$ & $(3)=(2)-(1)$ \\
& Academic high school & Vocational high school & $\begin{array}{l}\text { Difference } \\
\text { Low-income }\end{array}$ \\
Male & 0.40 & 0.31 & $-0.09^{* * *}$ \\
Age & 0.50 & 0.57 & 0.06 \\
Urban & 15.97 & 16.14 & $0.17^{* * *}$ \\
Student migrated & 0.88 & 0.90 & 0.01 \\
Siblings & 0.14 & 0.17 & $0.04^{* * *}$ \\
Parents home & 0.72 & 0.68 & -0.03 \\
Parents no junior high & 0.87 & 0.89 & 0.02 \\
Math baseline (z-score) & 0.29 & 0.40 & $0.11^{* * *}$ \\
Computer baseline (z-score) & 2.13 & 1.16 & $-0.97^{* * *}$ \\
\end{tabular}

\footnotetext{
${ }^{1}$ The academic high school students appear to be economically poorer than the vocational high school students in our sample. This is likely because we sampled second tier, nonelite academic high schools that enrolled students with characteristics more comparable to those in vocational high schools. In addition, students who do not qualify for academic high schools have two choices: they may enter the labor market or attend vocational high schools. Students entering the labor market are typically from poorer backgrounds than those going into vocational high (Song et al. 2013). That is, a number of vocational high school students were children who were unable to test well enough to enter academic high schools but came from richer families that did not need to send their children to the labor market.
}

Note: Cluster-robust SEs in parentheses; *** $\mathrm{p}<0.01, * \mathrm{p}<0.05$, , $\mathrm{p}<0.1$.

Source: Authors' analysis based on data described in the text.

as dropout rates or learning in vocational high schools could be due to the kinds of students who attend rather than the low quality of vocational high schools compared to (nonelite) academic high schools. Our analytical approach focuses on addressing this type of selection bias.

\subsection{Analytical Approach}

To assess the impact of attending vocational versus academic high school on student dropout rates, computing skills and math skills, we conduct three types of analyses: (a) ordinary least squares (OLS); (b) instrumental variable (or IV); and (c) matching analyses. Note that, in all three types of analyses, we estimate Huber-White standard errors that correct for prefecture-level clustering. ${ }^{10}$

\subsubsection{Ordinary least SQuares (OLS). Our first type of analysis uses OLS regres- sion. We conduct the OLS analysis to examine the basic relationship between the}

10. Although it would be most appropriate to adjust standard errors for clustering at the school level, we conservatively adjust for clustering at the higher levels of aggregation. In particular, we adjust for clustering at the prefecture level for the OLS and matching analyses (and the county level for the IV analyses) because we add in prefecture (county) fixed effects when estimating differences across treatment and control groups. In fact, the results of the paper are substantively the same whether we adjust the standard errors for clustering at the school level (without prefecture/county fixed effects) or prefecture/ county level (with prefecture/county fixed effects). Results are available from the authors on request. 
treatment (attending vocational versus academic high school) and student outcomes, while controlling for observable covariates that may confound that relationship. The basic specification for the OLS analysis is:

$$
Y_{i j}=\alpha_{0}+\alpha_{1} V_{i j}+\mathrm{X}_{\mathrm{ij}} \alpha+\tau_{p}+\varepsilon_{i j}
$$

where $\mathrm{Y}_{\mathrm{ij}}$ represents the outcome variable of interest (dropout, computing, or math skills) of student $i$ in school $j$. $V_{i j}$ is a dummy variable for whether or not student $i$ attended vocational high school at the time of the baseline survey. In the absence of omitted variables bias, $\alpha_{1}$ would be the treatment impact of attending vocational (versus academic) high school on $Y_{\mathrm{ij}}$.

The term $\mathrm{X}_{\mathrm{ij}}$ in equation (1) represents a vector of observable baseline covariates for student $i$ in school $j$. It includes student and family covariates such as male (equals 1 if the student is male and 0 if female), age (in days), urban (equals 1 if the student has urban residential permit status and 0 if rural), student migrated (equals 1 if the student has migrated prior to the baseline survey and 0 otherwise), siblings (equals 1 if the student has siblings and 0 otherwise), parents at home (equals 1 if both parents stayed at home between January 2011 to August 2011 and 0 otherwise), parents did not finish junior high (equals 1 if neither parent finished junior high school and 0 otherwise), and low-income (equals 1 if students are in the bottom $33 \%$ of the distribution of our family asset value variable and 0 otherwise). Importantly, we also control for baseline computer and math scores. Finally, we control for social, economic, and political differences in local context by adding a fixed effect term $\tau_{p}$ to indicate the prefecture where the student went to high school. ${ }^{11}$

2.3.2 Instrumental variables. For our second type of analysis, we conduct an instrumental variables (IV) analysis. We conduct the IV analysis because, in contrast to OLS, it can in theory produce causal estimates of the impact of vocational versus academic high school on student outcomes. In particular, whereas OLS fundamentally relies on the assumption of ignorability (that after controlling for observable pretreatment covariates, treatment assignment is independent of the outcome of interest), the IV analysis relies on two different assumptions (Murnane and Willett 2010). The first assumption is that of exogeneity: the IV should influence student outcomes only through the treatment variable (attending vocational versus academic high school) and not through any other channel. The second assumption is that the IV should be strongly correlated with the treatment variable in order to produce consistent treatment effect estimates. We discuss whether these two assumptions are met in our IV analysis immediately below.

11. The estimates of the impact of attending vocational schools on dropout in tables 2 and 3 are from a linear probability (OLS) model. Since dropout is a binary outcome, as a robustness check, we also estimated the impact using a logit model. The results from the logit model are substantively identical to the OLS results and are available upon request. 
Our IV analysis exploits variation in student HSEE scores relative to an HSEE score cutoff. In China, HSEE scores determine entry into academic high school. Every county has a different cutoff for whether a student's score makes him/her eligible to enter academic high school. Students with HSEE scores that are equal to or higher than the HSEE score cutoff in their county can go to academic high school. By contrast, students with HSEE scores that are lower than the cutoff can only go to vocational high school (or enter the labor market).

Significantly, while our approach is similar in spirit to a regression discontinuity design, we apply an IV strategy because standard sensitivity tests show that the typical RD design is not valid for our situation. In particular, due to the fact that we sampled (academic and vocational) high school students, the density of students that score just below the HSEE cutoff (to enter academic high school) is significantly less than the density of students that score just above the HSEE cutoff. This difference is not due to students' ability to manipulate their HSEE scores. Rather, the difference arises because a large proportion of students that scored under the HSEE cutoff and did not get into academic high school chose to enter the unskilled labor market (where wages are relatively high-see Cai et al. 2008) instead of vocational high school. Since our sample does not include students that chose to enter the unskilled labor market, the RD design is not strictly valid for our situation.

We instead rely on an IV estimation strategy that still leverages the HSEE cutoff for academic (versus vocational) high school. Namely, our IV estimation strategy takes advantage of the strict assignment rule associated with the HSEE cutoff and yet controls for a number of important baseline covariates that, because of sample selection bias, may be correlated with the treatment and the outcome variables of interest (see appendix S1 for a full discussion, appendix S1 in the supplemental appendix, available at http://wber.oxfordjournals.org/). We further check the robustness of our IV results to sample selection bias (see subsection 3.1.2).

To apply the IV analysis, we first create an instrumental variable called below cutoff. Below cutoff equals 1 if a student scored below the HSEE cutoff in the county in which he/she took the HSEE and 0 if otherwise. We attempted to collect information on HSEE score cutoffs from each county in our sample prefectures for 2011 (the year in which the vast majority of students in our sample took the HSEE). In the end, we were able to collect HSEE score cutoffs from twenty-one of the seventy-five total sample counties, and the IV analysis is only among these twenty-one counties. ${ }^{12}$ Note that the HSEE test scores are not comparable across different prefectures because each prefecture administers a different test. In addition, although students within the same prefecture take the same

12. To attempt to keep information from the other counties, we did in fact try to infer the cutoff points by looking at the distribution of HSEE scores and vocational versus academic high school entrants in each county. Unfortunately, we were unable to identify large jumps in entry at particular HSEE score values. Failing to identify these jumps, we surmise that these other counties did not use a strict cutoff rule to determine entry into academic high school. This may be the reason why officials in these counties did not publicly publish their HSEE cutoffs (and the reason that we could not obtain information about these cutoffs from the county officials themselves). 
HSEE, different counties within the same prefecture may use slightly different rules for grading the (same) HSEE test forms. For this reason, we always control for county fixed effects (using the county that each student took the HSEE in) when using our instrumental variable. By using below cutoff as an instrument for $\mathrm{V}_{\mathrm{ij}}$ in equation 1 , we assume that, conditional on baseline covariates, whether a student is below or above the HSEE cutoff exclusively affects his/her outcomes (dropout, specific skills, general skills) through his/her decision to attend vocational or academic high school. This is the exogeneity assumption of IV analysis.

We provide justification for why below cutoff may be an appropriate IV. Figures 1 map the relationship between each student's HSEE score (centered at the HSEE score cutoff in the county he/she took the HSEE, $\mathrm{x}$-axis) and the probability of attending vocational versus academic high school ( $V_{i j}$, y-axis). Figure 1 a shows that the probability of attending vocational high school drops by over $50 \%$ at the HSEE cutoff. By contrast, the probability of attending vocational high school only drops by $10 \%$ or less at ten points to the right or left of the HSEE cutoff (figures $1 \mathrm{~b}$ and $1 \mathrm{c}$ respectively). The probability of attending vocational high school hardly drops at all at twenty points to the right or left of the HSEE cutoff (figures $1 \mathrm{~d}$ and 1e respectively). Figures 1, taken together with the fact that county officials set HSEE cutoffs after the HSEE is administered and scored, lend support to the idea that (in the absence of sample selection bias), the HSEE cutoff rule is likely exogenous. If controlling for baseline covariates can appropriately adjust for sample bias, the HSEE cutoff variable should be uncorrelated with (observable and unobservable) factors that influence the relationship between vocational high school attendance $\left(\mathrm{V}_{\mathrm{ij}}\right)$ and student outcomes. In an attempt to control for possible sources of endogeneity, we control for $\mathrm{X}_{\mathrm{ij}}$, HSEE score, and county fixed effects in all of our IV analyses. ${ }^{13}$

Below cutoff also fulfills the second important assumption of IV analyses (Murnane and Willett 2010). Namely, the below cutoff variable is strongly correlated with $\mathrm{V}_{\mathrm{ij}}$ in the first stage of the IV regression (see appendix table S2 and appendix table $\mathrm{S} 2$ in the supplemental appendix, available at http://wber. oxfordjournals.org/). Specifically, the first stage results show that the instrument has a strong and statistically significant (at the $1 \%$ level) relationship with the endogenous regressor. The weak identification tests (using the Craig-Donald Wald F Statistic) all reject the null hypotheses that the equations are weakly identified (with a p-value $<0.01$ ).

2.3.3 CoARSENED EXACT MATCHING (CEM) ANALYSES. As a robustness check on our IV analyses and also to see whether our IV analyses hold over a broader range of data (i.e., because the IV analyses were only for students from twenty-one counties with HSEE cutoff data), our third analysis is a matching

13. It is true that a small number of students (eighty-six out of 1754 or less than $5 \%$ of students) scored below the cutoff and yet managed to enter academic high school. This small number of students may have (unofficially) paid high fees to enter academic high school. Nevertheless, this is the exception and not the rule. As such, this phenomenon should not substantively change our analyses. 
Figure 1. Graphs Showing the Discontinuity at the HSEE Cutoff (Between Attending Academic and Vocational High School) Figure 1a. At the HSEE Cutoff Figure 1b. 10 Points above the Cutoff Figure 1c. 10 Points below the Cutoff Figure 1d. 20 Points above the Cutoff Figure 1e. 20 Points below the Cutoff

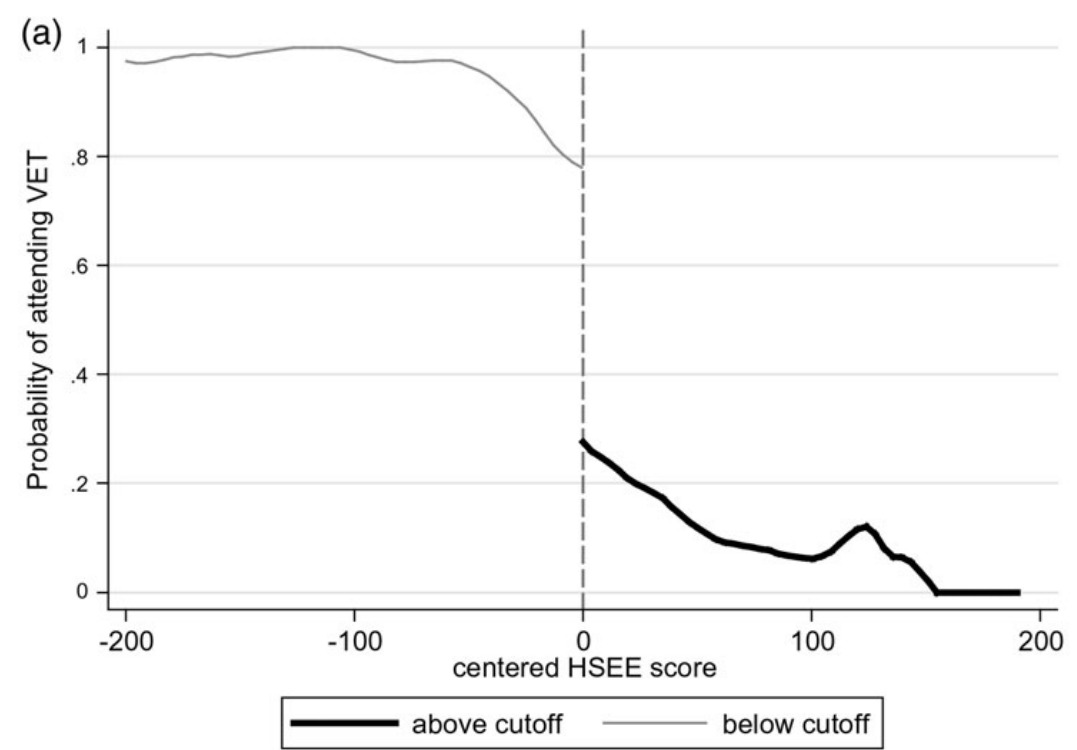

(b)

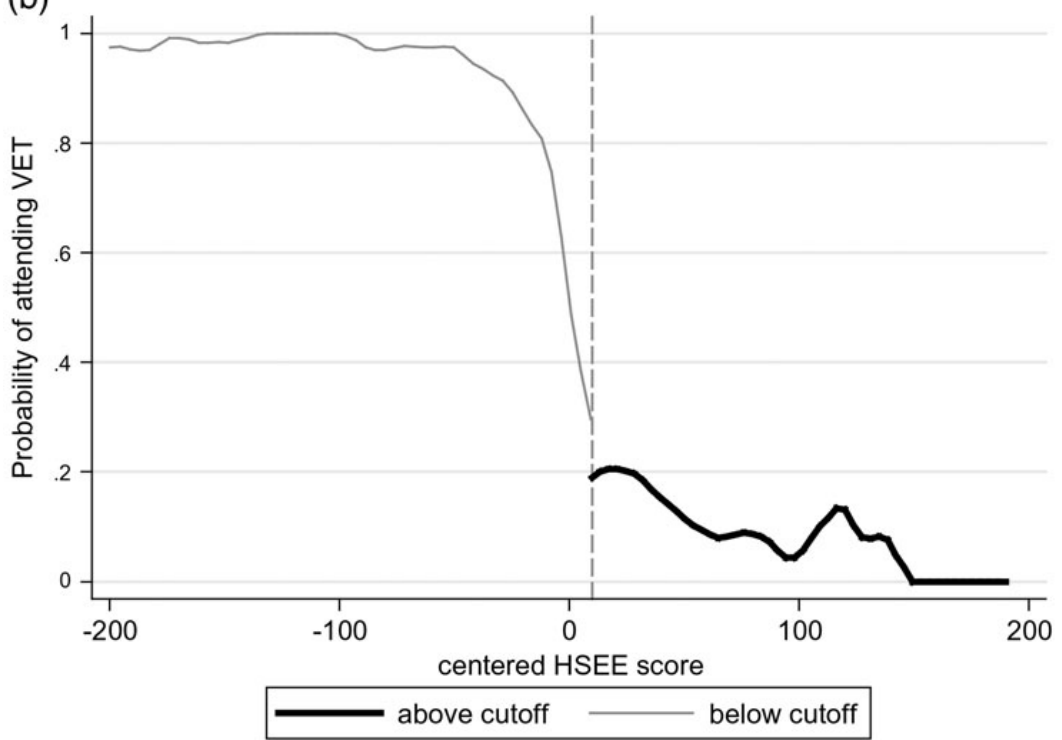

Source: Authors' analysis based on data described in the text. 


\section{Figure 1. Continued}
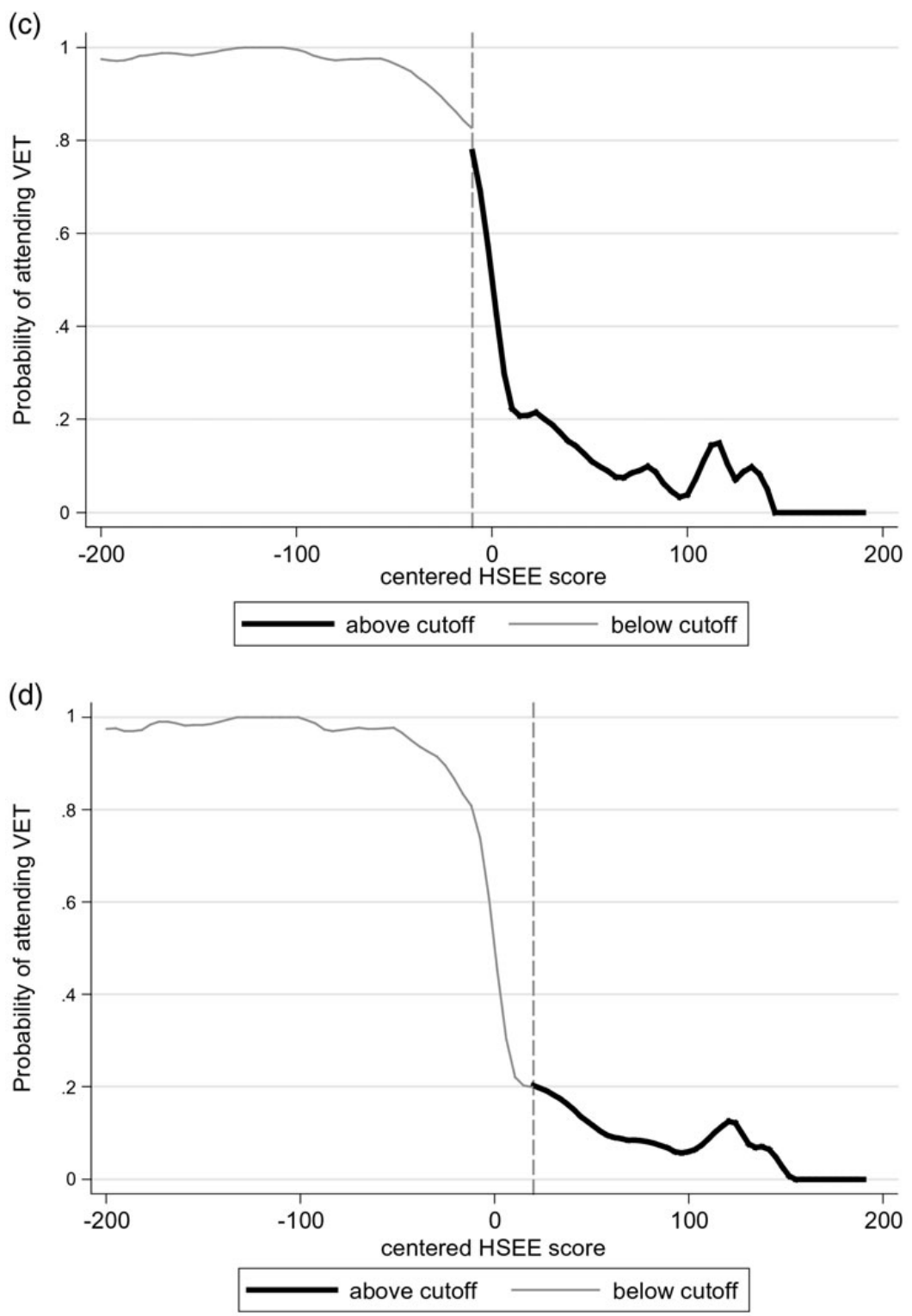

exercise. This third analysis isolates the sample of vocational and academic high school students that are similar on baseline characteristics by using coarsened exact matching or CEM. The CEM procedure is comprised of three steps. In step one, each variable is recoded (or "coarsened") so that substantively similar values of the variable are grouped and assigned the same numerical value. In step 


\section{Figure 1. Continued}

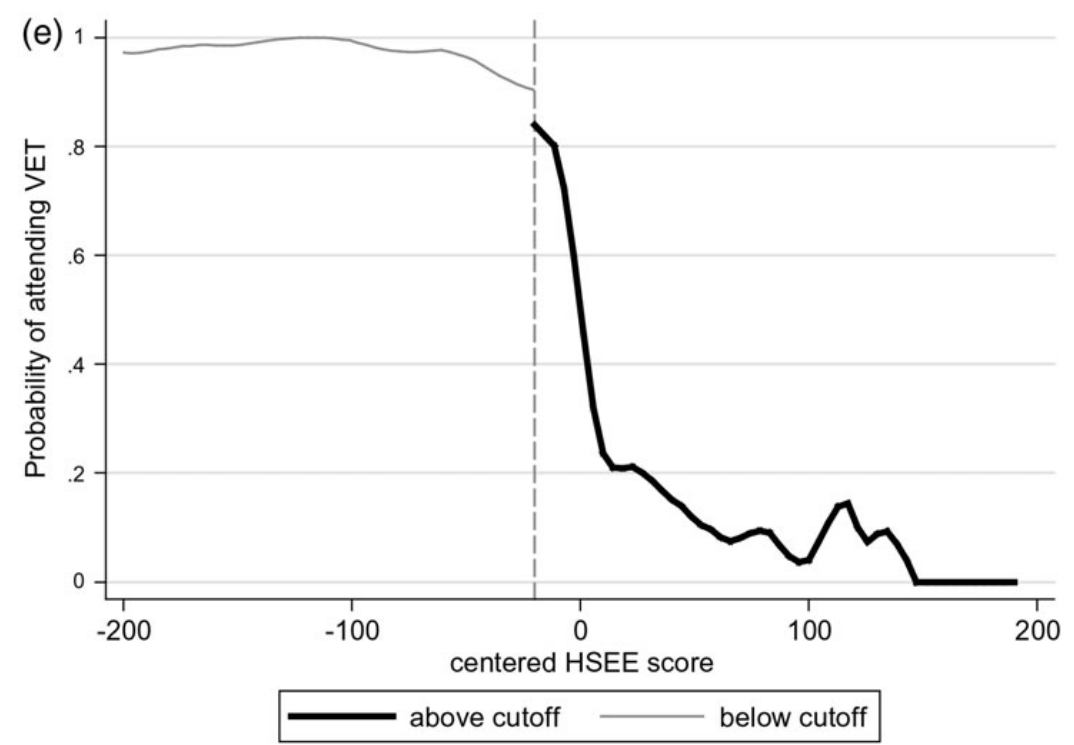

two, students are matched "exactly" on the coarsened data: if either a vocational high school student or an academic high school student does not find one or more matches on the coarsened data, that student is dropped from the sample. In step three, the data are "uncoarsened" or returned to their original values for the students that were not dropped from the sample. The post-matching estimation procedure is conducted on the data from step three.

Why do we choose CEM over traditional matching methods like propensity score matching? First and most importantly, compared to propensity score and Mahalanobis distance matching (which belong to the Equal Percent Bias Reducing or EPBR class of matching methods-Rosenbaum and Rubin 1985), CEM can obtain unbiased estimates with fewer restrictions on the data (see appendix S2 for a detailed discussion and appendix S2 in the supplemental appendix, available at http://wber.oxfordjournals.org/). As a result and as shown across a wide variety of datasets (see Iacus et al. 2011), CEM typically finds better balance in baseline characteristics across treatment and control groups than matching methods from the EPBR class. Second, CEM automatically eliminates the extrapolation region and thus (unlike matching methods in the EPBR class) does not require a separate procedure by which to restrict the data to a common support. Third, CEM is robust to measurement error. Fourth, CEM works with multiply imputed data. Fifth, CEM is computationally fast. A full discussion for how CEM outperforms propensity score and Mahalanobis distance matching is in appendix S2.

Given our choice to apply CEM, we make two substantive choices. First, we choose to match students from vocational (treatment) and academic (control) 
high schools on the baseline covariates $\mathrm{X}_{\mathrm{ij}}$ in equation (1). To ensure that we are comparing students who face similar educational choices within a similar local context, we also choose to match students (exactly) within the prefecture and year in which they took the high school entrance exam (HSEE).

Second, we also had to choose how much to coarsen each covariate (see appendix S2 for an explanation of coarsening). By way of example, we can choose to coarsen baseline math scores into quintiles, meaning that we can choose to create five equally sized bins of students based on the quintile of their baseline math score. It is by choosing how much to coarsen or bin each covariate (such as baseline math scores) that we can decide ex ante on the maximum amount of imbalance in covariates between the treatment and control groups. In our actual CEM analysis, we choose to coarsen the distributions of each of our baseline exam score variables (computing, math) into six equally spaced bins. We next coarsen age by year (where a year is defined by the calendar of a typical school year, e.g., from Sept. 1, 1985 to Aug. 31 1986). We also configure the CEM procedure to match students within (and not across) prefectures. All of the other covariates in $\mathrm{X}_{\mathrm{ij}}$ are dummy variables. As with exact matching, the CEM procedure uses the two values of each dummy variable to help create the bins on which we match treatment and control students.

The CEM procedure produces balance across the observable covariates. After applying the matching procedure, the vocational and academic high school students look similar on all of the baseline characteristics in equation 1 (appendix table S3 versus appendix table S4, and appendix table S3 and S4 in the supplemental appendix, available at http://wber.oxfordjournals.org/). As a robustness check, we also coarsen the baseline math and computer exam distributions into finer bins (from six up to fifteen bins each). Although the size of the matched sample decreases with the finer coarsening, we obtain similar results across the various matching specifications. The balance in baseline covariates is not just at the mean but also at different parts of the distribution of each covariate (see appendix table S2). Furthermore, as explained above, the use of CEM automatically ensures that the matched data share a common support. As such, we do not have to check to make sure that the matched data share a common support.

After matching the data using CEM, we run the same regression analyses as in equation (1) on the matched set of students. Like Iacus et al. (2011), we use doubly robust methods to estimate the causal effects: we use linear regressions (that adjust for baseline covariates) to estimate the impacts of attending vocational high school on student outcomes after matching the data. Our causal estimators are doubly robust in the sense that the estimators are unbiased if either the matching procedure or the regression specification is correctly specified (Ho et al. 2007). We call the regression analyses on the matched set of students our CEM analyses.

Granted, matching methods like CEM rely on the assumption of ignorability. That is, after controlling for observable covariates, no unobservable covariate is significantly correlated with both the treatment and outcome(s) of interest. While we cannot claim that CEM accounts for all possible confounding covariates, we 
believe that the CEM model presented here controls for the main confounding influences for why students attend vocational high school even when they are eligible to attend academic high school (see appendix S2 for more details).

\section{RESULTS}

\subsection{What is the Impact of Attending Vocational (Versus Academic) High School?}

3.1.1 Main Results. According to the results from the OLS analysis, students in vocational schools have different dropout rates and learn both computing and math skills at different rates than students from academic high schools. Specifically, students in vocational schools are 4 percentage points (or about 78 percent) more likely to drop out compared to students in academic high schools (table 2, row 1, column 1). The difference is statistically significant at the $1 \%$ level. The OLS regressions also show that students attending vocational high school do not improve computing skills more than students attending academic high school (row 1, column 2). Students in vocational high school scored only 0.02 SDs higher than academic high school students in computing skills (not statistically different from zero). Finally, in terms of math skills, students in vocational high school score far lower (0.44 SDs) than students in academic high school (row 1 , column 3). The difference is significant at the $1 \%$ level. In summary, students attending vocational versus academic high schools drop out more, learn fewer general skills, and have no measurable advantage in learning specific skills.

The results from our IV analysis generally support the story that vocational high schools do not build human capital (table 3). Vocational high school students are 1.1 percentage points more likely to drop out (although this finding on differences in the dropout rate-unlike the OLS finding - is no longer statistically significant). The IV estimates of vocational schooling on computing and math skills remain consistent with the findings from the OLS analysis. Vocational schooling reduces math skills by 0.30 SDs (a finding significant at the $1 \%$ level). Moreover, there is no statistically significant evidence that attending VET improves computing skills (an increase of $0.12 \mathrm{SDs}, \mathrm{p}=0.16$ ). The magnitude of the point estimate, even if it were statistically significant, is not large given the much greater number of class hours spent on learning computing in vocational schools compared to academic schools.

The results of the CEM analysis also tell the same story (table 4). Attending vocational high school increases dropout rates by 3 percentage points (over academic high school students- row 1, column 1). This finding is significant at the $1 \%$ level. Attending vocational high school has a negligible effect on computing skills. Although vocational high school students appear to do slightly worse than their academic high school peers on the computer skills exams (by 0.05 SDs), the estimated coefficient is not statistically significant (row 1, column 2). The CEM analysis-which matches similar students from vocational high school and 
Table 2. Impact of Attending Vocational High School (versus Academic High School) on Student Outcomes-OLS Regressions with Fixed Effects (on Unmatched Data)

\begin{tabular}{lccc}
\hline & $(1)$ & $(2)$ & $(3)$ \\
& Dropout & Computer endline & Math endline \\
\hline Went to VET & $0.04^{* * * *}$ & 0.02 & $-0.44^{* * * *}$ \\
Low-income & $(0.01)$ & $(0.05)$ & $(0.08)$ \\
& 0.00 & 0.01 & $0.05^{* * *}$ \\
Male & $(0.01)$ & $(0.01)$ & $(0.01)$ \\
& $0.03^{* * *}$ & 0.01 & $-0.05^{* *}$ \\
Age & $(0.01)$ & $(0.02)$ & $(0.02)$ \\
& $0.01^{* * *}$ & $-0.02^{* * *}$ & $-0.05^{* * *}$ \\
Urban & $(0.00)$ & $(0.00)$ & $(0.01)$ \\
& 0.01 & -0.03 & 0.01 \\
Student migrated & $(0.01)$ & $(0.04)$ & $(0.04)$ \\
& 0.01 & 0.02 & $0.06^{* *}$ \\
Siblings & $(0.01)$ & $(0.02)$ & $(0.04)$ \\
Parents home & $0.01^{* * *}$ & -0.01 & -0.02 \\
& $(0.00)$ & $(0.02)$ & $(0.03)$ \\
Parents no junior high school & $-0.04^{* * *}$ & 0.02 & -0.01 \\
& $(0.01)$ & $(0.02)$ & $(0.04)$ \\
Math baseline & $0.02^{* * *}$ & -0.01 & 0.03 \\
Computer baseline & $(0.01)$ & $(0.01)$ & $(0.03)$ \\
Observations & $-0.01^{* * *}$ & $0.05^{* * *}$ & $0.26^{* * *}$ \\
& $(0.00)$ & $(0.01)$ & $(0.02)$ \\
& 0.00 & $0.33^{* * *}$ & $0.19^{* * *}$ \\
\hline
\end{tabular}

Note: Cluster-robust SEs in parentheses; $* * \mathrm{p}<0.01, * \mathrm{p}<0.05, * \mathrm{p}<0.1$.

Source: Authors' analysis based on data described in the text.

academic high schools-demonstrates that attending vocational high school decreases math skills by 0.42 SDs (significant at the $1 \%$ level-row 1 , column 3 ).

Taken together, our findings demonstrate that attending vocational high school actually hurts students relative to attending academic high school. First, vocational high school encourages drop out (or at least does not encourage students to stay in school). Second, vocational high schools are failing to equip students with computing skills relative to academic high schools (which spend little class time teaching computing). Third, attending vocational versus academic high school results in a loss of math skills.

3.1.2 Robustness CHECKS. To test the sensitivity of our estimates, we conduct six sets of robustness checks. Our first set of robustness checks tests whether our IV analyses are robust when we adjust our IV estimation strategy in four ways: (a) add nonlinear controls of the running variable; (b) allow slopes to be different on either side of the cutoff; (c) limit the sample to students that are closer to (on either side of) the cutoff; and (d) relax the assumption of linearity by using a probit model. Our second set of robustness checks involves defining our sample 
TA B LE 3. Impact of Attending Vocational High School (versus Academic High School) on Student Outcomes (IV Analyses, 2011 HSEE Takers from 21 Counties)

\begin{tabular}{|c|c|c|c|}
\hline & $\begin{array}{c}(1) \\
\text { Dropout }\end{array}$ & $\begin{array}{c}(2) \\
\text { Computer Endline }\end{array}$ & $\begin{array}{c}\text { (3) } \\
\text { Math endline }\end{array}$ \\
\hline Went to VET & $\begin{array}{c}0.01 \\
(0.03)\end{array}$ & $\begin{array}{c}0.12 \\
(0.08)\end{array}$ & $\begin{array}{l}-0.30 * * * \\
(0.11)\end{array}$ \\
\hline Low-income & $\begin{array}{c}0.01 \\
(0.01)\end{array}$ & $\begin{array}{r}-0.01 \\
(0.02)\end{array}$ & $\begin{array}{c}0.02 \\
(0.03)\end{array}$ \\
\hline Male & $\begin{array}{c}0.01 \\
(0.01)\end{array}$ & $\begin{array}{l}0.06 * * * \\
(0.02)\end{array}$ & $\begin{array}{l}0.09^{* * * *} \\
(0.04)\end{array}$ \\
\hline Age & $\begin{array}{l}0.01^{* *} \\
(0.00)\end{array}$ & $\begin{array}{c}-0.01 \\
(0.02)\end{array}$ & $\begin{array}{l}-0.08 * * * \\
(0.02)\end{array}$ \\
\hline Urban & $\begin{array}{r}-0.003 \\
(0.01)\end{array}$ & $\begin{array}{c}-0.07 * * \\
(0.03)\end{array}$ & $\begin{array}{r}0.005 \\
(0.06)\end{array}$ \\
\hline Student migrated & $\begin{array}{c}0.01 \\
(0.01)\end{array}$ & $\begin{array}{c}0.02 \\
(0.03)\end{array}$ & $\begin{array}{c}0.01 \\
(0.05)\end{array}$ \\
\hline Siblings & $\begin{array}{c}0.01 \\
(0.01)\end{array}$ & $\begin{array}{c}0.03 \\
(0.03)\end{array}$ & $\begin{array}{c}0.04 \\
(0.04)\end{array}$ \\
\hline Parents home & $\begin{array}{l}-0.03 * * * \\
(0.01)\end{array}$ & $\begin{array}{c}0.02 \\
(0.02)\end{array}$ & $\begin{array}{c}-0.04 \\
(0.05)\end{array}$ \\
\hline Parents no junior high school & $\begin{array}{c}0.00 \\
(0.01)\end{array}$ & $\begin{array}{r}-0.02 \\
(0.02)\end{array}$ & $\begin{array}{c}0.01 \\
(0.02)\end{array}$ \\
\hline Math baseline & $\begin{array}{c}0.00 \\
(0.00)\end{array}$ & $\begin{array}{l}0.02 * * \\
(0.01)\end{array}$ & $\begin{array}{l}0.17 * * * \\
(0.01)\end{array}$ \\
\hline Computer baseline & $\begin{array}{c}0.01 \\
(0.01)\end{array}$ & $\begin{array}{l}0.30 * * * \\
(0.04)\end{array}$ & $\begin{array}{l}0.13^{* * *} \\
(0.03)\end{array}$ \\
\hline Centered HSEE score & $\begin{array}{l}-0.00 * * \\
(0.00)\end{array}$ & $\begin{array}{l}0.00 \% * * \\
(0.00)\end{array}$ & $\begin{array}{l}0.00^{* * *} \\
(0.00)\end{array}$ \\
\hline Observations & 3,600 & 3,303 & 3,303 \\
\hline
\end{tabular}

Note: Cluster-robust SEs in parentheses; ${ }^{* *} \mathrm{p}<0.01,{ }^{* *} \mathrm{p}<0.05,{ }^{*} \mathrm{p}<0.1$.

Source: Authors' analysis based on data described in the text.

differently: (a) by excluding dropouts from analyses of the impact of vocational (versus academic) high school on skills; and (b) by using a multiple imputation procedure to fill in (or predict) the missing outcome values of the dropout students and thereafter including these students in our analyses. A third set of checks involves ascertaining whether our estimates are sensitive to attrition, which we test for using Lee Bounds. A fourth set of robustness checks involves checking whether defining our variables differently (as continuous rather than binary variables, for example) would change our results. A fifth set of robustness checks tests whether sample selection could bias our IV estimates. Sixth (and related to the sample selection issue), we use a procedure suggested by Conley et al. (2012) to test the sensitivity of our IV estimates to deviations from the exogeneity assumption. In all cases, the results are not substantively different from the results from the models presented in the paper. While we do not display these results in the body of the text for the sake of brevity, they are presented in the 
TA B be 4. Impact of Attending Vocational High School (versus Academic High School) on Student Outcomes-OLS Regressions on Matched Data

\begin{tabular}{lccc}
\hline & $(1)$ & $(2)$ & $(3)$ \\
& Dropout & Computer endline & Math endline \\
\hline Went to VET & $0.03^{* * * *}$ & -0.05 & $-0.42^{* * * *}$ \\
Low-income & $(0.01)$ & $(0.08)$ & $(0.09)$ \\
Male & -0.00 & 0.05 & -0.01 \\
& $(0.01)$ & $(0.03)$ & $(0.04)$ \\
Age & $0.04^{* * *}$ & 0.05 & $-0.07^{* * *}$ \\
& $(0.01)$ & $(0.06)$ & $(0.03)$ \\
Urban & 0.01 & -0.04 & $-0.07^{* * *}$ \\
& $(0.01)$ & $(0.03)$ & $(0.03)$ \\
Student migrated & $0.02^{* *}$ & -0.12 & 0.03 \\
& $(0.01)$ & $(0.15)$ & $(0.09)$ \\
Siblings & $0.04^{* * *}$ & -0.02 & $0.24^{* * *}$ \\
Parents home & $(0.02)$ & $(0.02)$ & $(0.08)$ \\
& 0.01 & $0.10^{* * *}$ & $-0.11^{* * *}$ \\
Parents no junior high school & $(0.01)$ & $(0.04)$ & $(0.05)$ \\
& -0.03 & -0.03 & -0.05 \\
Math baseline & $(0.05)$ & $(0.05)$ & $(0.10)$ \\
& $0.03^{* * *}$ & -0.06 & -0.00 \\
Computer baseline & $(0.01)$ & $(0.06)$ & $(0.09)$ \\
& $-0.01^{* *}$ & $0.04^{* * *}$ & $0.22^{* * *}$ \\
Observations & $(0.01)$ & $(0.01)$ & $(0.02)$ \\
& -0.01 & $0.33^{* * * *}$ & $0.19^{* * * *}$ \\
\hline
\end{tabular}

Note: Cluster-robust SEs in parentheses; ${ }^{* * *} \mathrm{p}<0.01, * \mathrm{p}<0.05, * \mathrm{p}<0.1$.

Source: Authors' analysis based on data described in the text.

appendixes (appendix S3, appendix table S5, and appendix table S6 in the supplemental appendix, available at http://wber.oxfordjournals.org/).

\subsection{The Impact of Vocational High Schools on Low-Income and Low-Ability Students}

According to some policy documents (e.g., MOF and MOE 2006), vocational high schools are meant to benefit low-income and low-ability students. In this section, we examine the heterogeneous impacts of attending vocational (versus academic) high school on dropout rates and skills by income (poverty) level and ability. To do so, we rerun two additional versions of the IV analyses (one with an additional treatment-low-income interaction term; and one with an additional treatment-low-ability interaction term).

Our results show that low-income students not only fail to benefit from attending vocational high school, they actually perform worse (table 5). Low-income students who attend vocational versus academic high school are 5.9 percentage points more likely than higher income students to drop out (significant at the $10 \%$ level—column 1). Furthermore, like the average student (as 
TA B LE 5. Heterogeneous Impacts of Attending Vocational High School (versus Academic High School) on Low-income Student Outcomes (IV Analyses, 2011 HSEE Takers from 21 Counties)

\begin{tabular}{|c|c|c|c|}
\hline & $\begin{array}{c}(1) \\
\text { Dropout }\end{array}$ & $\begin{array}{c}(2) \\
\text { Computer endline }\end{array}$ & $\begin{array}{c}\text { (3) } \\
\text { Math endline }\end{array}$ \\
\hline Went to VET & $\begin{array}{c}0.00 \\
(0.03)\end{array}$ & $\begin{array}{c}0.12 \\
(0.08)\end{array}$ & $\begin{array}{c}-0.30 * * \\
(0.12)\end{array}$ \\
\hline VET*Low-income & $\begin{array}{l}0.06 * \\
(0.03)\end{array}$ & $\begin{array}{c}-0.05 \\
(0.05)\end{array}$ & $\begin{array}{c}0.00 \\
(0.09)\end{array}$ \\
\hline Low-income & $\begin{array}{c}-0.02 \\
(0.02)\end{array}$ & $\begin{array}{c}0.01 \\
(0.03)\end{array}$ & $\begin{array}{c}0.02 \\
(0.05)\end{array}$ \\
\hline Male & $\begin{array}{c}0.01 \\
(0.01)\end{array}$ & $\begin{array}{l}0.06^{* * *} \\
(0.02)\end{array}$ & $\begin{array}{l}0.09 * * \\
(0.04)\end{array}$ \\
\hline Age & $\begin{array}{l}0.01^{* *} \\
(0.00)\end{array}$ & $\begin{array}{c}-0.01 \\
(0.02)\end{array}$ & $\begin{array}{c}-0.08 * * * \\
(0.02)\end{array}$ \\
\hline Urban & $\begin{array}{c}0.00 \\
(0.01)\end{array}$ & $\begin{array}{c}-0.07 * * \\
(0.03)\end{array}$ & $\begin{array}{c}0.00 \\
(0.06)\end{array}$ \\
\hline Student migrated & $\begin{array}{c}0.01 \\
(0.01)\end{array}$ & $\begin{array}{c}0.02 \\
(0.03)\end{array}$ & $\begin{array}{c}0.01 \\
(0.05)\end{array}$ \\
\hline Siblings & $\begin{array}{c}0.01 \\
(0.01)\end{array}$ & $\begin{array}{c}0.03 \\
(0.03)\end{array}$ & $\begin{array}{c}0.04 \\
(0.04)\end{array}$ \\
\hline Parents home & $\begin{array}{c}-0.03 * * * \\
(0.01)\end{array}$ & $\begin{array}{c}0.02 \\
(0.02)\end{array}$ & $\begin{array}{c}-0.04 \\
(0.05)\end{array}$ \\
\hline Parents no junior high school & $\begin{array}{c}0.00 \\
(0.01)\end{array}$ & $\begin{array}{c}-0.02 \\
(0.02)\end{array}$ & $\begin{array}{c}0.01 \\
(0.02)\end{array}$ \\
\hline Math baseline & $\begin{array}{c}0.00 \\
(0.00)\end{array}$ & $\begin{array}{l}0.02 * * \\
(0.01)\end{array}$ & $\begin{array}{l}0.17^{* * * *} \\
(0.01)\end{array}$ \\
\hline Computer baseline & $\begin{array}{c}0.00 \\
(0.01)\end{array}$ & $\begin{array}{l}0.30 * * * \\
(0.04)\end{array}$ & $\begin{array}{l}0.13^{* * *} \\
(0.03)\end{array}$ \\
\hline Centered HSEE score & $\begin{array}{c}-0.00 * * \\
(0.00)\end{array}$ & $\begin{array}{l}0.00 * * * \\
(0.00)\end{array}$ & $\begin{array}{l}0.00 * * * \\
(0.00)\end{array}$ \\
\hline Observations & 3,600 & 3,303 & 3,303 \\
\hline
\end{tabular}

Note: Cluster-robust SEs in parentheses; $* * \mathrm{p}<0.01, * \mathrm{p}<0.05, * \mathrm{p}<0.1$.

Source: Authors' analysis based on data described in the text.

shown in the subsection above), low-income students make negligible gains in computing skills (column 2) while losing in math skills (column 3).

As with our results for low-income students, attending vocational high school has negative impacts on low-ability students. Low-ability students who attend vocational versus academic high school are more likely to dropout than higher ability students (the dropout rate increases by 2.5 percentage points for every 1 SD decrease in baseline computer scores-table 6, column 1). In addition, by attending vocational (versus academic) high school, low-ability students are even less likely to gain computing skills compared to higher ability students (the endline computer scores decrease by 0.13 SDs for every $1 \mathrm{SD}$ decrease in baseline computer scores-column 2). Finally, by attending vocational (versus academic) high school, low-ability students may see their math skills deteriorate more than higher ability students (by .06 SDs for every 1 SD 
TA B LE 6. Heterogeneous Impacts of Attending Vocational High School (versus Academic High School) on Low-Ability Student Outcomes (IV Analyses, 2011 HSEE Takers from 21 Counties)

\begin{tabular}{|c|c|c|c|}
\hline & $\begin{array}{c}(1) \\
\text { Dropout }\end{array}$ & $\begin{array}{c}(2) \\
\text { Computer Endline }\end{array}$ & $\begin{array}{c}(3) \\
\text { Math endline }\end{array}$ \\
\hline Went to VET & $\begin{array}{c}0.02 \\
(0.03)\end{array}$ & $\begin{array}{c}0.09 \\
(0.08)\end{array}$ & $\begin{array}{l}-0.31 * * * \\
(0.11)\end{array}$ \\
\hline VET*computer_baseline & $\begin{array}{r}-0.03 * \\
(0.02)\end{array}$ & $\begin{array}{l}0.13 * * * \\
(0.04)\end{array}$ & $\begin{array}{c}0.06 \\
(0.06)\end{array}$ \\
\hline Male & $\begin{array}{c}0.01 \\
(0.01)\end{array}$ & $\begin{array}{l}0.06^{* * *} \\
(0.02)\end{array}$ & $\begin{array}{l}0.09 * * \\
(0.04)\end{array}$ \\
\hline Age & $\begin{array}{l}0.01 * * \\
(0.00)\end{array}$ & $\begin{array}{c}-0.01 \\
(0.02)\end{array}$ & $\begin{array}{l}-0.08 * * * \\
(0.02)\end{array}$ \\
\hline Urban & $\begin{array}{c}0.00 \\
(0.01)\end{array}$ & $\begin{array}{c}-0.07 * * \\
(0.03)\end{array}$ & $\begin{array}{c}0.00 \\
(0.06)\end{array}$ \\
\hline Student migrated & $\begin{array}{c}0.01 \\
(0.01)\end{array}$ & $\begin{array}{c}0.02 \\
(0.03)\end{array}$ & $\begin{array}{c}0.01 \\
(0.05)\end{array}$ \\
\hline Siblings & $\begin{array}{c}0.01 \\
(0.01)\end{array}$ & $\begin{array}{c}0.03 \\
(0.03)\end{array}$ & $\begin{array}{c}0.04 \\
(0.04)\end{array}$ \\
\hline Parents home & $\begin{array}{l}-0.03^{* * *} \\
(0.01)\end{array}$ & $\begin{array}{c}0.02 \\
(0.02)\end{array}$ & $\begin{array}{c}-0.04 \\
(0.05)\end{array}$ \\
\hline Parents no junior high school & $\begin{array}{c}0.00 \\
(0.01)\end{array}$ & $\begin{array}{r}-0.02 \\
(0.02)\end{array}$ & $\begin{array}{c}0.01 \\
(0.02)\end{array}$ \\
\hline Low-income & $\begin{array}{c}0.01 \\
(0.01)\end{array}$ & $\begin{array}{c}-0.01 \\
(0.02)\end{array}$ & $\begin{array}{c}0.02 \\
(0.03)\end{array}$ \\
\hline Math baseline & $\begin{array}{c}0.00 \\
(0.00)\end{array}$ & $\begin{array}{l}0.02^{* *} \\
(0.01)\end{array}$ & $\begin{array}{l}0.17 * * * \\
(0.01)\end{array}$ \\
\hline Computer baseline & $\begin{array}{l}0.02^{* * *} \\
(0.01)\end{array}$ & $\begin{array}{l}0.24 * * * \\
(0.04)\end{array}$ & $\begin{array}{l}0.10^{*} \\
(0.06)\end{array}$ \\
\hline Centered HSEE score & $\begin{array}{r}-0.00^{*} \\
(0.00)\end{array}$ & $\begin{array}{l}0.02 * * * \\
(0.00)\end{array}$ & $\begin{array}{l}0.03 * * * \\
(0.00)\end{array}$ \\
\hline Observations & 3,600 & 3,303 & 3,303 \\
\hline
\end{tabular}

Note: Cluster-robust SEs in parentheses; $* * \mathrm{p}<0.01,{ }^{*} \mathrm{p}<0.05$, , $\mathrm{p}<0.1$.

Source: Authors' analysis based on data described in the text.

decrease in baseline computer scores, although the result is not statistically significant at the $10 \%$ level-column 3 ).

Taken together, the findings indicate that attending vocational high school may hurt disadvantaged (low-income and low-ability) students even more than their advantaged counterparts. Low-income and low-ability students who attend vocational (rather than academic) high school drop out more than the higher income and ability students. There is also some evidence to indicate that lowincome and low-ability students are even less likely to gain computing skills than higher income and higher ability students and at least as likely to see a reduction in their math skills compared to higher income and higher ability students. These findings are true even though vocational schools are (by design) supposed to benefit such students. For this reason, according to our results, we conclude that lowincome and low-ability students would have fared better in academic high schools. 


\subsection{IRT Gains in General and Specific Skills}

The results in the previous subsections demonstrate that attending vocational high school has a negative impact on student outcomes. However, our analysis can go further. Because our standardized exams were vertically scaled using IRT, we are able to analyze the individual gains in general and specific skills for the sample vocational and academic high school students. This analysis will help us determine if vocational high school students are learning.

Surprisingly, the IRT-scaled gains show that vocational high school students are actually losing math skills (figure 2 ). ${ }^{14}$ The IRT-scaled math scores of students in vocational high school fell by 0.08 SDs from the beginning to the end of grade 10. By contrast, students in academic high schools gained 0.04 SDs in math over the same period. ${ }^{15}$ In other words, the results show that vocational high school students are not only falling behind academic high school students, they are actually losing skills they previously had.

There are somewhat more encouraging results in terms of specific skills. According the IRT-scaled test results, vocational high school students make modest gains in computer skills (figure 3). On average, the IRT-scaled computer scores of vocational high school students rose by 0.12 SDs. However, as would be expected (from the subsections above), vocational high school students made fewer gains in specific skills than academic high school students, even as they spend much less time in computer classes than their vocational counterparts. The computer scores of academic high school students (in nonelite academic high schools) rose by 0.23 SDs. ${ }^{16}$

These results suggest that, in absolute terms, vocational high schools make only small contributions to or may even detract from human capital development. While it is true that vocational high school students make modest gains in their computing skills, as a whole their gains are less than those in academic high

14. In fact, this graph only examines the IRT-scaled math gains among the lowest scoring $50 \%$ of students at the baseline. We make this adjustment because our baseline results were right-censored (a ceiling effect). Including these students would have biased the estimate of gains upward, as students scoring full marks at the baseline actually could have scored higher. In spite of this adjustment and ceiling effect, our main analytic models which compare the impact of vocational versus academic high school are unaffected.

15. What explains the surprising result that academic high school students are learning so little math and vocational high school students are learning so little in computers? One reason to suspect that academic high school students learned so little mathematics is that our schools are nonelite academic high schools, where the quality of schooling is not always high. Another reason for the low mathematics gains for academic high school students is that they were entering a new school (their first year of high school). As is common in the United States, for example, students entering a new schooling environment may have muted learning gains as they adjust to their new environment (e.g., see Roderick and Camburn 1999).

16. Why did academic high school students appear to make higher gains in computers even compared to mathematics? Students have a minimum exposure to computers in junior high school. As such, their first real exposure to computers comes at the high school level. Hence, even though academic high schools only reserve one course for computers per week, the first systematic exposure to computers may have resulted in higher gains compared to mathematics. In addition, although it may appear peculiar that vocational high school students were learning fewer computer skills than academic high school students, the fact that the tests were constructed to match national standards suggests that vocational high schools were simply not teaching well (or students were not learning well). 
Figure 2. Gains in IRT-scaled Math Scores: Academic vs. Vocational High School

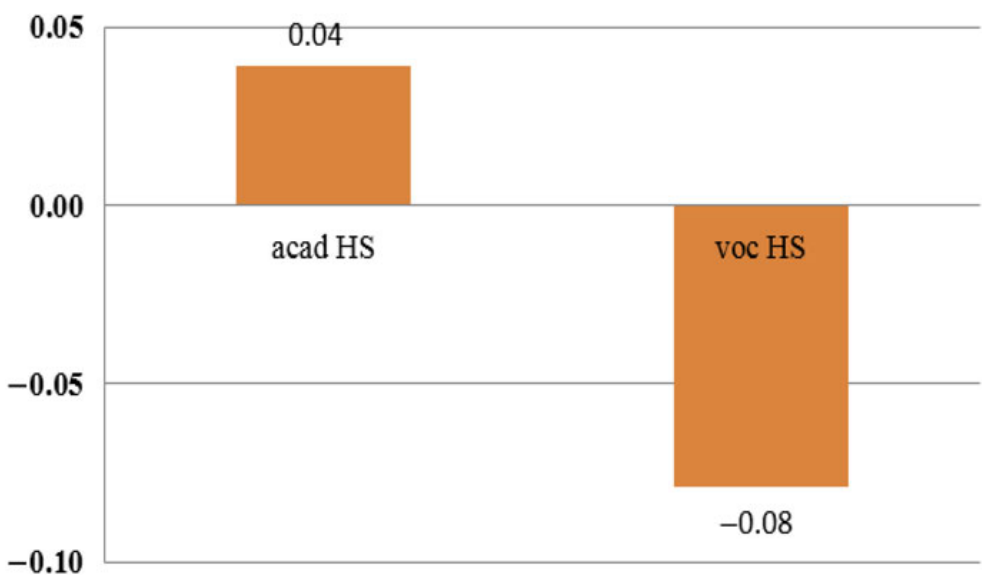

Note: Figure 2 shows the raw difference before controlling for any background characteristics Source: Authors' analysis based on data described in the text.

school. More importantly, vocational high school students are actually losing math skills.

\section{CONCLUSION}

Overall, VET at the high school level does appear to be meeting its mandate of equipping students with the human capital needed to succeed in China's future economy. Specifically, attending vocational high school appears to cause students (in the computer major) to drop out of school if they are of low-income and of low-ability. Our results also show that attending vocational high school has no significant effect on specific skills and a substantial, negative impact on general skills relative to attending academic high school. This negative impact is pronounced among both low-income students and low-ability students. Finally, in absolute terms, vocational high school even detracts from students' math skills over the course of the first year (from the start to the end of grade ten). If our results generalize to other provinces and majors, vocational high schools are failing to contribute to human capital development in China. ${ }^{17}$

17. It is conceivable that the students were performing poorly in vocational school because they were still adjusting to a new environment. While we do not have longer-term follow-up data of our sample students, we do have the dropout rate of the cohort of students in our sample over time. We started in the baseline with a total of 7,114 vocational high school students in our sample. Of these, 649 dropped out at the end of the first year (as noted in this paper). By the second year, an additional 751 students dropped out. That is a cumulative dropout rate of $20 \%$ over the first two years. (For comparison, the estimated two-year dropout rate in academic high schools is 5\%-Loyalka et al., 2014). If students, in fact, felt like they were learning at the second year, the assumption is that it would have reduced the dropout rate. Since the dropout rate was even more serious in the second year, we conjecture that students were not learning more in their second year (assuming that other factors influencing dropout were also constant across the two years). 
Figure 3. Gains in IRT-scaled Computer Scores: Academic vs. Vocational High School

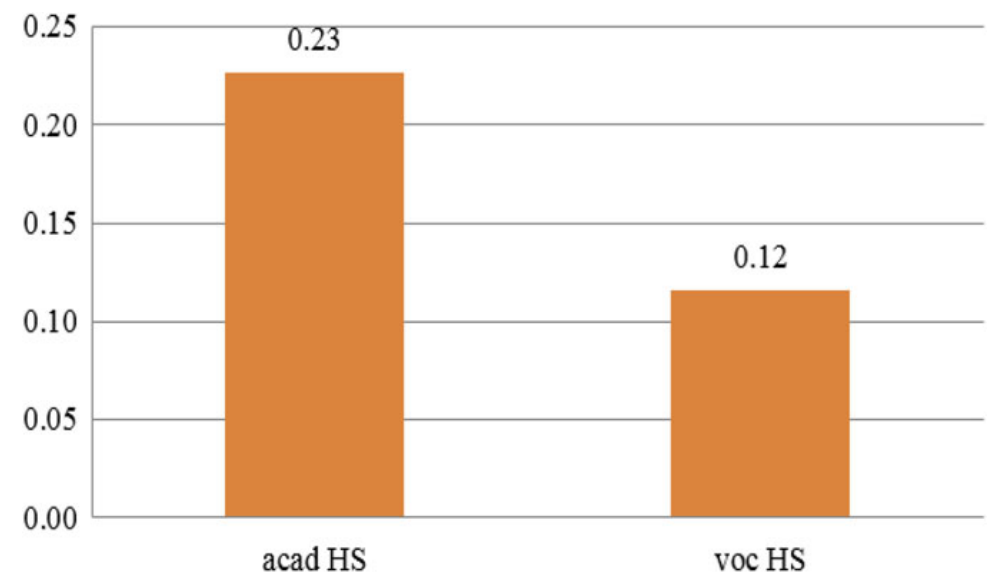

Note: Figure 3 shows the raw difference before controlling for any background characteristics. Source: Authors' analysis based on data described in the text.

There are reasons to believe that these results are conservative. First, in our more robust models (the IV and matching estimates), we are actually comparing students around the HSEE cutoff. ${ }^{18}$ One implication of this method is that our results generalize to the "cream of the crop" in vocational high school. These are primarily students who scored high enough to be within reach of attending academic high school. If we were to use a counterfactual that allowed us to estimate the effect of attending vocational high school on all vocational high school students, the negative effects of vocational high school might be even larger.

Second, when selecting our sample, we chose schools with relatively large and stable enrollments in the computing major. If enrollments correlate with the quality of the school (as they do in academic schooling in China), our sample consists of higher-quality schools. If we estimated the effects of attending vocational high school among all vocational high schools, the negative impacts on dropout and skills would be even larger.

Overall, the lack of value-added in math or computing skills is likely to mute or decrease future labor market payoffs. Granted, it could be that vocational high schools produce value-added in noncognitive (or social and behavioral) skills, such that there is still a net labor market return even without value-added in general or specific (cognitive) skills. In fact, Kim (2013) finds positive labor market returns on vocational education in Korea. However, the fact that Chinese computer major students are losing their math skills and barely learning any

18. The reason is that students who scored at the bottom of the HSEE distribution have no opportunity to enter academic high school, thus making the assumption that they were randomly assigned to academic high school not credible. Likewise, students who score at the top of the HSEE distribution almost never attend vocational high school. 
computing skills suggests that they also may not be acquiring social or behavioral skills either. ${ }^{19}$

Why does VET at the high school level appear to fail at generating human capital? While a full discussion of this question is beyond the scope of this study, one argument is that local governments (who are responsible for financing vocational high schools) are still failing to invest sufficient resources into vocational high schools. A related argument is that local governments favor academic over vocational high schools and deny appropriate resources like qualified teachers or finances to the latter (Yang 2012).

In fact, evidence suggests that this is not the case. We compare the vocational and academic high schools across a set of inputs-including the percentage of teachers with a college degree; the percentage of teachers with professional experience; computers per student; total school area (in square meters) per student; whether the school has laboratories; libraries or multimedia rooms; and expenditures per student (in RMB). We find that, with one exception, there are no substantial or statistically significant differences between vocational high schools and academic high schools (appendix table S7). The exception is that vocational high schools have more computers per student. As such, vocational high schools appear to be on equal (if not marginally better) footing with academic high schools in terms of basic inputs.

A second possibility is a lack of coordination and oversight to ensure the transformation of inputs (e.g., financial investments) into outputs (e.g., student skills). Multiple ministries/departments/bureaus oversee vocational education, thus reducing coordination and sharing of best practices between schools. Moreover, none of the ministries/departments/bureaus have developed protocols to systematically monitor vocational high school quality in a standard fashion. As such, there is almost no oversight over the quality of these schools.

A limitation of our study is that we focus only on students in the computer major and only test their math and computer skills. Ideally, our study would have included students in other majors and tested a wider set of skills. Therefore, strictly speaking, our results do not apply to other majors and other types of skills in vocational schooling in China. However, if our findings on quality are generally true and if the reasons for this poor quality are as we surmise, policymakers in China may wish to cease the large, almost indiscriminate investment into the vocational high school system. Instead they may wish to direct more resources toward the apparently more effective approach to human capital development: academic high school.

19. If the value-added of vocational high schools was so low, why did students still attend? While we cannot be sure, we conjecture that the failure of the government to provide clear, public (or open) information on the quality of schools has created information asymmetries. That is, students may not have actually known what the quality of the schools was before they decided to attend. As such, students believed that they would learn skills when they began vocational high schools (even if, on average, this was not true). 
Furthermore, the results of this study should give pause to policymakers seeking to promote VET in other developing countries. Our results show that, at the margin, students in the most popular major in vocational school in two Chinese provinces lose general skills without any apparent gain in specific skills. While our results do not strictly apply to other developing countries, the fact that our findings are consistent with results from Indonesia (Chen 2009) and Romania (Malamud and Pop-Eleches 2008) suggests that other developing countries with substantial investments in vocational secondary education may also fail to enjoy significant returns to their investment. By diverting resources away from academic high school, developing countries may be reducing the number of students who can access a human-capital enhancing opportunity to attend academic high school. Together, such a policy could substantially hinder human capital production.

\section{REFERENCES}

Altinok, N. 2011. “General Versus Vocational Education: Some New Evidence from PISA 2009. Paper Commissioned for the EFA Global Monitoring Report 2012, Youth and Skills: Putting Education to Work." Access date: July 25, 2015. Available from unesdoc.unesco.org/images/0021/002178/217873e.pdf.

Bresnahan, T. F., E. Brynjolfsson, and L. M. Hitt. 2002. "Information Technology, Workplace Organization, and the Demand for Skilled Labor: Firm-level Evidence." The Quarterly Journal of Economics 117 (1): 339-76.

Cai, F., A. Park, and Y. Zhao. 2008. “The Chinese Labor Market in the Reform Era.” In L. Brandt, and T. Rawski, eds., China's Economic Transition: Origins, Mechanisms, and Consequences, Cambridge: Cambridge University Press.

Chen, D. 2009. "Vocational Schooling, Labor Market Outcomes, and College Entry.” Policy Research Working Paper 4814. Washington, DC: World Bank.

China State Council. 2010. "National Education Reform and Development Outline (2010-2020)." Access date: July 20, 2015. Available at http://www.gov.cn/jrzg/2010-07/29/content_1667143.htm (in Chinese).

Chinese Ministry of Education. 2008. "Standards for Instruction in the Major: Required Facilities and Equipment for the Computer Application Majors." Access date: September 4, 2014. Available at http://www.moe.edu.cn/publicfiles/business/htmlfiles/moe/moe_963/201001.

Chiswick, B. R., Y. L. Lee, and P. W. Miller. 2003. "Schooling, Literacy, Numeracy and Labour Market Success." Economic Record 79 (245): 165-81.

Conley, T. G., C. B. Hansen, and P. E. Rossi. 2012. "Plausibly Exogenous." Review of Economics and Statistics 94(1): 260-72.

Hanushek, E. A., and L. Woessmann. 2012. "Schooling, Educational Achievement, and the Latin American Growth Puzzle.” Journal of Development Economics 99 (2): 497-512.

Heckman, J. J., and J. Yi. 2012. "Human capital, economic growth, and inequality in China." National Bureau of Economic Research. Working paper No. w18100.

Ho, D., K. Imai, G. King, and Elizabeth Stuart. 2007. "Matching as Nonparametric Preprocessing for Reducing Model Dependence in Parametric Causal Inference.” Political Analysis 15 (3): 199-236.

Iacus, S. M., G. King, and G. Porro. 2011. "Multivariate Matching Methods That Are Monotonic Imbalance Bounding." Journal of the American Statistical Association 106 (493): 345-61.

Kézdi, G. 2006. "Not Only Transition: The Reasons for Declining Returns to Vocational Education." Center for Economic Research \& Graduate Education-Economics Institute, 15. 
Kim, B. M. 2013. “Estimating Returns to Vocational Education at High Schools in Korea.” USC Working Paper.

King, G., and L. Zeng. 2006. “The Dangers of Extreme Counterfactuals.” Political Analysis 14 (2): 131-59.

Kolen, M. J., and R. L. Brennan. 2004. Test Equating, Scaling, and Linking: Methods and Practices (2nd ed.). New York, NY: Springer.

Kolenikov, S., and G. Angeles. 2009. "Socioeconomic Status Measurement with Discrete Proxy Variables: Is Principal Component Analysis a Reliable Answer?" Review of Income and Wealth 55 (1): 128-65.

Kuczera, M., G. Brunello, S. Field, and N. Hoffman. (2008). "Learning for Jobs OECD Reviews of Vocational Education and Training." Paris: OECD.

Levy, F., and R. J. Murnane. 2004. "Education and the Changing Job Market.” Educational Leadership $62(2): 80$.

Loyalka, P., J. Chu, J. Wei, N. Johnson, J. Reniker, and S. Rozelle. 2014. “Mapping Inequality in the Pathway to College in China: What Happens after Junior High School?” REAP Working Paper \#277.

Malamud, O., and C. Pop-Eleches. 2008. "General Education vs. Vocational Training: Evidence from an Economy in Transition," Working Papers 0807, Harris School of Public Policy Studies, University of Chicago.

Ministry of Finance (MOF) and Ministry of Education (MOE). 2006. "Comments Regarding the Expansion of Secondary Vocational School Financial Aid for Poor Families." Access date: July 20, 2015. Available at http://www.edu.cn/zong_he_801/20060817/t20060817_192408.shtml. (in Chinese).

Ministry of Finance (MOF) and National Bureau of Statistics (NBS). (2011). China Educational Finance Statistical Yearbook. Bejing: China Statistics Press.

Murnane, R. J., and J. B. Willett. 2010. Methods Matter: Improving Causal Inference in Educational and Social Science Research. New York: Oxford University Press, USA.

National Congress of Brazil. 2011. "Institui o Programa Nacional de Acesso ao Ensino Técnico e Emprego (Pronatec)." Law 10.

National Bureau of Statistics. Various years. China Statistical Yearbook (various years). China Statistics Press, Beijing. (in Chinese).

Newhouse, D., and D. Suryadarma. 2011. "The Value of Vocational Education: High School Type and Labor Market Outcomes in Indonesia.” The World Bank Economic Review 25 (2): 296-322.

Roderick, M., and E. Camburn. 1999. "Risk and Recovery from Course Failure in the Early Years of High School.” American Educational Research Journal 36 (2): 303-43.

Rosenbaum, P. R., and D. B. Rubin. 1985. "Constructing a Control Group using Multivariate Matched Sampling Methods that Incorporate the Propensity Score.” The American Statistician 39: 33-38.

Song, Y., P. Loyalka, and J. Wei. 2013. "Determinants of Tracking Intentions, and Actual Education Choices Among Junior High School Students in Rural China.” Chinese Education o Society 46 (4): $30-42$.

Yang, J. 2012. "Exploration on the models of vocational school operation (zhiye jiaoyu banxue moshi zhi wojian).” Time Report (Shidai Baogao) 8: 425. (In Chinese). 